\title{
Maternal and perinatal outcome of teenage deliveries in Bamako's district
}

\author{
Tiounkani Théra ${ }^{1 *}$, Niani Mounkoro², Ibrahim Téguété2, Aminata Kouma ${ }^{3}$, Zouma O. Traoré4, \\ Ibrahim Kanté ${ }^{1}$, Elizabeth Diarra ${ }^{4}$
}

\author{
${ }^{1}$ Department of Gynecology and Obstetrics of Point G, Mali \\ ${ }^{2}$ Department of Gynecology and Obstetrics of Gabriel Toure, Mali \\ ${ }^{3}$ Department of Gynecology and Obstetrics of Kati, Mali \\ ${ }^{4}$ Department of Gynecology and Obstetrics and Bamako's V References Health Centre, Mali
}

Received: 24 August 2017

Accepted: 25 September 2017

\author{
*Correspondence: \\ Dr. Tiounkani Théra, \\ E-mail: tiounkani@gmail.com
}

Copyright: (C) the author(s), publisher and licensee Medip Academy. This is an open-access article distributed under the terms of the Creative Commons Attribution Non-Commercial License, which permits unrestricted non-commercial use, distribution, and reproduction in any medium, provided the original work is properly cited.

\begin{abstract}
Background: We initiated this study for determining the maternal and fatal outcome of deliveries among the teenage to formulate the recommendations for reducing the maternal and neonatal morbidity and mortality among the teenage. We compared maternal and foetal outcome of deliveries among the teenage to that of adult women.

Methods: It was a prospective analytical case/control study running in the Bamako's district for 6 month comparing deliveries among one population of teenage elderly of 14-19 years and another population of women of 20 to 29 years having birth in our service hang the same period of the study. Used test statistics is the chi square of Pearson. For both groups we determined Odds Ratio (OR) and its interval of confidence (IC) to $95 \%$.

Results: We recorded 350 teenagers' deliveries among 3703 deliveries (9.4\%). The pelvic was normal among $66.3 \%$ of case versus $73.5 \%$ among the controls $(\mathrm{p}>0.05)$. The extended labor ( $\geq 12$ hours) was found among $6.6 \%$ of case versus $3.3 \%$ of controls ( $\mathrm{p}>0.05$ ). We recorded $57.3 \%$ vaginal deliveries among the case versus $46.2 \%$ among the controls $(\mathrm{p}>0.05)$. We recorded 3 cases of maternal death all among the controls. $71 \%$ of new-born had an Apgar score $\geq 7$ to the first minute among the case versus $81.2 \%$ among the controls. It was no significant difference in terms of vital outcome of new-born and of small weight birth in both groups ( $p>0.05)$.

Conclusions: If teenage pregnancies are benefit the adequate prenatal care, there would be any significant difference between maternal and perinatal outcome of the deliveries among the teenage and of adult's people.
\end{abstract}

Keywords: Deliveries, Maternal outcome, Perinatal outcome, Teenage

\section{INTRODUCTION}

According to the world health organization (WHO), the adolescence includes the elderly of 10 to 19 years. Although these births have place in all environment, 12.8 million $(90 \%)$ took place in the undeveloped country. ${ }^{1}$ Some favourable circumstances are the weak level school, the low social status, the no desired pregnancy associates to the immaturity of the organism and at bad level of prenatal care among the teenager. This circumstance increases the risk of pregnancies among teenagers. ${ }^{1,2}$ Among the girls of less of 15 years, the risk is multiplied by five. ${ }^{3}$ For each maternal death, you account also one thirty cases of complications, linked to the prematurity or small birthweight, of perinatal and infant mortality, of preeclampsia, anaemia, extended delivery, dystocia and of haemorrhage. ${ }^{3}$ However recent studies have shown that correctly followed, these pregnancies have the same outcome than the adulthood., ${ }^{2,3}$ That is why we initiated this study for determining the 
maternal and fetal outcome of deliveries among the teenage to formulate the recommendations for reducing the maternal and neonatal morbidity and mortality among the teenage.

\section{METHODS}

It was a prospective case/control study running in Bamako's V References Health Center at September 2013 to February 2014 and comparing the deliveries among a population of teenage elderly of 14-19 years and other population of women of 20 to 29 years having birth in our service in the same period of the study. It was about the $2^{\text {nd }}$ reference center having 14 community health centers whose 9 were functional during the period of the study. We recorded one case for two controls. We didn't include in this study the deliveries having in other service then referred secondary our service and the incomplete records. The data were recorded on the Word 2010 software and analyzed on SPSS 2.0 and EPI. Info 6.4 fr. For both groups we determined Odd Ratio (OR) and its interval of confidence (IC) to $95 \%$. The value of $\mathrm{p}$ $<0.05$ was considered as statistically significant.

\section{RESULTS}

We recorded 350 teenage deliveries among 3703 deliveries at Bamako's Reference Health Centre (9.4\%). The married have presented $68.7 \%$ among the cases versus $92.2 \%$ among the controls ( $p<0.001)$. We recorded $61.7 \%$ of housewives among the case versus $60.3 \%$ among the controls $(\mathrm{p}>0.05)$.

Table 1: Running of deliveries among both groups.

\begin{tabular}{|c|c|c|c|c|c|c|}
\hline \multirow{2}{*}{ Deliveries } & \multicolumn{2}{|c|}{ Cases $=\mathbf{3 0 0}$} & \multicolumn{4}{|c|}{ Controls $=600$} \\
\hline & Eff $^{\mathbf{a}}$ & $\%$ & Eff $^{\mathrm{a}}$ & $\%$ & $\mathbf{p}$ & OR-IC \\
\hline \multicolumn{7}{|l|}{ Admission } \\
\hline Themselves & 263 & 77.7 & 480 & 80.0 & 0.72 & $0.89(0.42-1.85)$ \\
\hline Evacuated & 37 & 22.3 & 120 & 20.0 & 0.72 & $1.13(0.54-2.35)$ \\
\hline \multicolumn{7}{|c|}{ Term of pregnancy } \\
\hline In the term & 178 & 59.3 & 449 & 74.8 & 0.02 & $1.13(0.26-0.95)$ \\
\hline Not in the term & 122 & 40.7 & 151 & 25.2 & 0.01 & $2.08(1.09-1.37)$ \\
\hline \multicolumn{7}{|l|}{ Form of pelvic } \\
\hline Asymmetric & 0 & 0.0 & 2 & 0.3 & - & - \\
\hline Normal & 199 & 66.3 & 441 & 73.5 & 0.28 & $0.72(0.37-1.37)$ \\
\hline limit & 75 & 25.0 & 130 & 21.7 & 0.61 & $1.18(0.58-2.39)$ \\
\hline Small & 26 & 8.7 & 27 & 4.5 & 0.15 & $2.37(0.64-9.53)$ \\
\hline \multicolumn{7}{|l|}{ Duration of labor } \\
\hline$<12 \mathrm{~h}$ & 282 & 94 & 580 & 96.7 & 0.30 & $0.48(0.09-2.26)$ \\
\hline$\geq 12 \mathrm{~h}$ & 18 & 6.0 & 20 & 3.3 & 0.32 & $2.02(0.43-10.54)$ \\
\hline \multicolumn{7}{|l|}{ Way of delivery } \\
\hline Vaginal & 172 & 57.3 & 277 & 46.2 & 0.11 & $1.56(0.86-2.83)$ \\
\hline Caesarean section & 128 & 42.7 & 323 & 53.8 & 0.11 & $0.64(0.35-1.17)$ \\
\hline
\end{tabular}

$\mathrm{a}=$ effective

In both groups, more of half of patients were unschooled $(58.3 \%)$ for the case versus $50.2 \%$ for the controls ( $p$ $>0.05$ ). However, pregnancies were desired among $62 \%$ of case versus $89.7 \%$ of controls ( $p<0.001$ ). The admission mode was the more often references $(77.7 \%)$ among the case versus $80 \%$ among the controls ( $p>0.05)$ (Table 1).

Additionally, we recorded $40.7 \%$ of premature deliveries among the case versus $25.2 \%$ among the controls ( $\mathrm{p}$ $<0,05$ ) (Table 1). The clinical examination has found a normal obstetrical pelvic among $66.3 \%$ of case versus 73 , $5 \%$ among the controls ( $\mathrm{p}>0,05$ ) (Table 1). The extended labor ( $\geq 12$ hours) was found among $6.6 \%$ of case versus $3.3 \%$ of controls ( $p>0.05$ ) (Table 1$)$. We recorded $57.3 \%$ of vaginal deliveries among the case versus $46.2 \%$ of the controls ( $p>0.05$ ).

We recorded $2.7 \%$ postpartum complications among the case vs $3.3 \%$ among the controls ( $>0.05$ ) (Table 2). Among these complications we recorded 5 cases of perineum tears $(1.7 \%)$ among the case versus $3(0.5 \%)$ among the controls and one case of uterine rupture among the controls. We recorded 3 maternal deaths, all among the controls (Table 2).

The most part of new-born had an Apgar score $\geq 7$ to the $1^{\text {st }}$ minute $(71 \%)$ among the case versus $81.2 \%$ among the controls and the stillbirth was found among $2.7 \%$ of case versus $3.5 \%$ of controls ( $p>0.05$ ). The small birth weight (weight $<2500 \mathrm{~g}$ ) have found in $26.7 \%$ in the group of 
case versus $18.2 \%$ among the controls ( $p>0,05)$. The vital outcome of new-born was good in $65 \%$ among the case versus 74\% among the controls ( $p>0.05$ ) (Table 3).

Table 2: Maternal outcome.

\begin{tabular}{|c|c|c|c|c|c|c|}
\hline \multirow[t]{2}{*}{ Outcome } & \multicolumn{2}{|c|}{ Cases $=\mathbf{3 0 0}$} & \multicolumn{4}{|c|}{ Controls $=600$} \\
\hline & Eff $^{\mathbf{a}}$ & $\%$ & Eff $^{\mathbf{a}}$ & $\%$ & p & OR-IC \\
\hline \multicolumn{7}{|c|}{ Post partum compl ${ }^{b}$} \\
\hline Yes & 8 & 2.7 & 20 & 3.3 & 0.65 & $0.66(0.08-4.99)$ \\
\hline No & 292 & 97.3 & 580 & 96.7 & 0.65 & $1.52(0.20-13.28)$ \\
\hline \multicolumn{7}{|l|}{$\begin{array}{l}\text { Type of } \\
\text { complications }\end{array}$} \\
\hline Tears of perineum & 5 & 1.7 & 3 & 0.5 & - & - \\
\hline Uterine rupture & 0 & 0.0 & 1 & 0.2 & - & - \\
\hline \multicolumn{7}{|l|}{ Maternal death } \\
\hline Yes & 0 & 0 & 3 & 0.5 & - & - \\
\hline No & 300 & 100 & 697 & 99.5 & & \\
\hline \multicolumn{7}{|c|}{ Cause maternal death } \\
\hline Haemorrhage & 0 & 0 & 1 & 0.2 & - & - \\
\hline Uterine rupture & 0 & 0 & 1 & 0.2 & - & - \\
\hline Septicaemia & 0 & 0 & 1 & 0.2 & - & - \\
\hline
\end{tabular}

$\mathrm{a}=$ effective; $\mathrm{b}=$ complication

Table 3: Perinatal outcome.

\begin{tabular}{|c|c|c|c|c|c|c|}
\hline \multirow{2}{*}{ Apgar's score ${ }^{a}$} & \multicolumn{2}{|c|}{ Cases $n=250$} & \multicolumn{4}{|c|}{ Controls $\mathrm{n}=\mathbf{5 0 0}$} \\
\hline & Eff $^{\mathbf{a}}$ & $\%$ & Eff $^{\mathbf{a}}$ & $\%$ & $\boldsymbol{P}$ & OR-IC \\
\hline 0 & 8 & 2.7 & 21 & 3.5 & 0.70 & $0.74(0.13-4.06)$ \\
\hline$<7$ & 79 & 26.3 & 92 & 15.3 & 0.05 & $1.99(0.28-4.29)$ \\
\hline$\geq 7$ & 213 & 71 & 487 & 81.2 & 0.09 & $0.57(0.28-1.17)$ \\
\hline \multicolumn{7}{|l|}{ Weight (g) } \\
\hline$\geq 2500$ & 220 & 73.3 & 491 & 81.8 & 0.12 & $0.59(0.29-1.23)$ \\
\hline$<2500$ & 80 & 26.7 & 109 & 18.2 & 0.12 & $1.68(0.82-3.50)$ \\
\hline \multicolumn{7}{|l|}{ Taille (cm) } \\
\hline$\geq 47$ & 243 & 81 & 505 & 84.2 & 0.37 & $0.71(0.31-1.61)$ \\
\hline$<47$ & 57 & 19 & 95 & 15.8 & 0.57 & $1.23(0.56-2.72)$ \\
\hline \multicolumn{7}{|c|}{ Condition of new born } \\
\hline Atterm & 260 & 86.7 & 556 & 92.7 & 0.15 & $0.50(0.17-1.43)$ \\
\hline Hypotrophy & 22 & 7.3 & 24 & 4.0 & 0.35 & $1.81(0.40-7.63)$ \\
\hline Premature & 18 & 6.0 & 20 & 3.3 & 0.30 & $2.06(0.44-10.76)$ \\
\hline \multicolumn{7}{|c|}{ Vitaloutcomeat $\mathrm{J7}^{\mathrm{c}}$} \\
\hline Good & 195 & 65.0 & 444 & 74.0 & 0.16 & $0.65(0.34-1.25)$ \\
\hline Dead & 8 & 2.7 & 23 & 3.8 & 0.70 & $0.74(0.13-4.06)$ \\
\hline Referred & 97 & 32.3 & 133 & 22.2 & 0.11 & $1.67(0.85-3.30)$ \\
\hline
\end{tabular}

$\mathrm{a}=\operatorname{Apgar} 1^{\text {st }} \mathrm{mn} ; \mathrm{b}=$ Apgar $1^{\text {st }} \mathrm{mn} ; \mathrm{c}=7$ days

\section{DISCUSSION}

The rate relatively high of deliveries among the teenage in the present study $(9.4 \%)$ is characteristic of undeveloped country and more particularly the Africans countries. This was found in the previous studies of Iloki LH at Congo and Tall A. in Senegal. ${ }^{2,4}$ Additionally Dedecker $\mathrm{F}$ has found $4 \%$ of births among the teenage of 13 to 17 years to the Reunion Island. ${ }^{5}$ The occurrence teenage pregnancy is also influenced by cultural factors.
Thus, in the study of Corcoran et al about 105 adolescents following one program of prevention of pregnancies in United States, the ethnic membership (Hispanic) to been one factor predictive of an pregnancy to the adolescence. ${ }^{6}$

Faucher $\mathrm{P}$ et al have analyzed retrospectively 62 records of deliveries at 13 to 17 years. ${ }^{7}$ The majority of patients are elderly of 16 and 17 years $(92 \%)$ and $46.8 \%$ was of originating of sub-Saharan Africa. 
Epidemiological and sociological studies have confirmed a correlation between the bad social integration and the early parenting. ${ }^{8}$ Thus we found $61.7 \%$ of housewives among the case versus $60.3 \%$ among the controls $(p>0.05)$ and $58.3 \%$ patients unschooled among the case versus $50.2 \%$ among the controls ( $p>0.05$ ). The frequency of complications of teenage pregnancies and their outcome, are fact always the object of debate. We haven't recorded any significant difference not only on the frequency of clinically normal pelvic $(\mathrm{p}=0.28)$ but also on the occurred of extended labor $(p=0.32)$. Additionally, Dedecker F says that condition for optimal monitoring of them pregnancies the teenage seem better to give birth than the young people adults and would be less subject to some specific pathologies of the pregnancy. ${ }^{5}$ That is found in the present study with $42.7 \%$ of caesarean among the teenage versus $53.7 \%$ of controls ( $p>0.05$ ). The rate of caesarean is higher than that of Tall A. at Senegal $(20 \%){ }^{4}$

The high rate of caesarean is explained by the fact that the present study took place in a reference health center that receives the patients referred of community health centers with obstetrical complications. However, the most part of teenage was referred of fact of them teenage. That explains the fact that the rate of caesarean is higher among the controls $(53.7 \%)$ versus among the case $(42.7 \%)$. The present results coincide with those found by the French National College of Gynecologists and Obstetricians (CNGOF) according to which the teenage delivery is, in all the studies, deemed without risk to condition that the pregnancy was recognized and some work of parenting were developed before delivery. ${ }^{9}$ That is found in the present study because it was, for the most part, of married teenage $(68 \%)$ and having a desire of child $(62 \%)$. The study of CNGOF has reported a large majority of vaginal deliveries $(91.3 \%)$ among which $18.5 \%$ of instrumental extractions and only $8.8 \%$ of cesareans sections. ${ }^{9}$

The old notion according to which the delivery through the teenage pelvic with completed growth could present a most risk of disproportions is not found in the facts. This trend is found in the literature including in Europe with Raatikainenk et al who has found $16.7 \%$ of caesarean section among the teenage versus $13.0 \%$ and $5.7 \%$ instrumental extraction versus $7.0 \% .{ }^{10}$ Hamada $\mathrm{H}$ and $\mathrm{Al}$ at Morocco has found $6.1 \%$ caesarean section among teenager versus $9.7 \%$ among the controls and $37.32 \%$ instrumental extraction versus $27.14 \% .{ }^{11}$ Gortzak-uzan L and AL in Israel, despite the youngest age of its patients (13-17 years), doesn't found any difference in term of the way of childbirth. ${ }^{12}$

The specific complications of the pregnancy more often found in the literature were the pre-eclampsia and the anemia. These complications were found in the studies of Tal Aabd et al at Senegal and Mahavarkar SH et al in India with respectively $17.5 \% ; 25 \%$ and $\mathrm{OR}=2.2,95 \%$ $\mathrm{CI}=1.5-3.2,(\mathrm{p}<0.0001)$ and $(\mathrm{OR}=2.83,95 \% \mathrm{CI}=2.2-$
3.7, $\mathrm{p}<0.0001)^{4,13}$ Additionally the more part of authors found no significant difference between both groups. $3,5,11,13,14$ That is found in the present study with $2.7 \%$ of complications nursery among the teenage versus $3.3 \%$ among the controls $(\mathrm{p}>0.05)$. We recorded 5 cases $(1.7 \%)$ of perineum tears of among the case versus 3 $(0.5 \%)$ among the controls. Additionally, 1 case of uterine rupture and 3 cases of maternal death were recorded all in the group of controls. However the study of Mahavarkar et al concluded that the complications of teenage pregnancies could be linked not only at young age, but also, to unfavorable socioeconomic conditions of teenage. ${ }^{13}$ The study of Mahfouz AR et al conducted in Saudi Arabia has compared the teenage to a group controls having the same number of prenatal care $(6.6 \pm 1.1$ and $6.7 \pm 1.2) .{ }^{14} \mathrm{He}$ concluded that teenage pregnant are not a group to most risk when they benefit of adequate prenatal care. That seems finding in the present study because $68 \%$ of teenage were married and $62 \%$ having desire of child.

The epidemiological and sociological studies have confirmed this vision in showing a correlation between bad social integration and early parenting. ${ }^{7}$ Elsewhere the 3-maternal death occurred among the witnesses were related to of nursery complications having required their evacuation at health reference center. It was about a case of uterine rupture, one case of postpartum hemorrhage and one case of septicemia. In the present study, the vital outcome of newborn was good in $65 \%$ among the case versus $74 \%$ among the controls $(\mathrm{p}>0.05)$. This rate is lower to that of Iloki $\mathrm{H}$ et al at Congo who had found $53 \%$ the teenage versus $14 \%$ among the controls. ${ }^{5}$ The perinatal outcome found in the present study is similar to that of Faucher $\mathrm{P}$ et al who has recorded $93.5 \%$ of eutrophic new-born to term; $98.5 \%$ of good vital outcome of new-born. Uzan in its report in 1998 has reported a rate of intra uterine growth retardation of $13 \% .^{3}$ That is superior at rate of hypotrophy found in the present study $(7.3 \%)$. That could be nutritional explained by the deficits more frequent of fact of vomiting more frequent in beginning of pregnancy and later of fact of unfavorable socioeconomic conditions. ${ }^{15}$

Mahfouz AR says that the pregnancy among the teenager is not a pregnancy to high risks in outside of conditions unfavorable socioeconomic who it's accompany. ${ }^{14}$ Even if Dedecker $F$ accepts that condition an optimal monitoring of pregnancy the teenage seem better give birth than the young adults and would be less subject to some specific pathologies of the pregnancy. He however recorded in his study a stronger risk of childbirth of great premature $(<32 \mathrm{~W})$ incidence $3,6 \%$ versus $1.6 \%$, OR 2.3 , $\mathrm{p}=0.008) .{ }^{15}$ That is found in the study of Tal $\mathrm{A}$ at Senegal who has reported that one new-born on two has presented at least a fetal distress or a weight to the birth < 2500 g. ${ }^{4}$ Likewise Ilokil $\mathrm{H}$ et al at Congo has reported that the childbirth premature was 3 times among teenage and that the new-born: hypotrophy had represented 22,1 versus $15.7 \%$ among the controls. ${ }^{2}$ Hamada $\mathrm{H}$ et al at 
Morocco has recorded $10 \%$ of small weight birth (weight $<2500 \mathrm{~g}$ ) with a middleweight among the singles versus 3098 among married. ${ }^{11}$ The social factor would have therefore a significant impact on the weight birth.

\section{CONCLUSION}

If teenage pregnancies are benefit the adequate prenatal care, there would be any significant difference between maternal and perinatal outcome of the deliveries among the teenage and of adult's people.

\section{ACKNOWLEDGMENTS}

The authors would like to thank all the staff at Bamako's V References Center for the support of the study.

Funding: No funding sources

Conflict of interest: None declared

Ethical approval: The study was approved by the Institutional Ethics Committee

\section{REFERENCES}

1. OMS. Regional Office for Europe. Symposium on the identification of high-risk individuals and population groups. Windsor 1970; Copenhagen. 1973

2. Iloki LH, Koubaka RC, Itoua GM, Mbemba M. Pregnancy and childbirth in the Congo adolescent: About 276 cases at the CHU in Brazzaville. J Gynécol Obstet Biol Reprod. 2004;33(1):37-42.

3. Uzan M. Report on prevention and management of teenage pregnancies. Period 1994-1998. Report of the head of Gynecology-Obstetrics Department of the Jean Verdier hospital in Bondy. France, Inserm. 1998

4. Tal DA, Diallo I, Guillemin F, Deschamps FP.

5. Prognostic factors of complications of pregnancy and childbirth in adolescent girls and their newborns in Senegal. 2001;11(4).

6. Dedecker F, de Bailliencourt T, Barau G. Study of obstetric risk factors in the follow-up of 365 teenage primiparous pregnancies on the island of La Réunio. J Obstet Gynecol Reprod. 2005;34(7)(1):694-701.
7. Corcoran J, Franklin C, Bennett P. Ecological factors associated with adolescent pregnancy and parenting. Social Work Research. 2000;24(1):29-39.

8. Faucher P, Dappe S, Madelenat P. Maternity in adolescence: obstetrical analysis and review of the influence of cultural, socio-economic and psychological factors from a retrospective study of 62 files. Gynecology Obstetrics 2002;30(12):944-52.

9. Le Van C. Pregnancy in adolescence: Social norms, realities experienced. 1999:153.

10. Blanc B. Pregnancy and childbirth. National College of Gynecologists and Obstetricians. Updates in Medical Gynecology. 2003:209-24.

11. Raatikainen K, Heiskanen N, Verkasalo PK, Heinonen S. Good outcome of teenage pregnancies in high-quality maternity care. Eu J Pub Health. 2005;16(2):157-61.

12. Hamada H, Zaki A, Nejjar H. Pregnancy and Childbirth in Adolescents: Characteristic and Profile. About 311 cases. J Gynecol Obstet Biol Reprod. 2004;33:607-14.

13. Gortzak-Uzan L, Hallak M, Press F, Katz M, Shoham-Vardi. Teenage pregnancy: risk factors for adverse perinatal outcome. J Maternal-Fetal Neonatal Med. 2001;10(6):393-7.

14. Mahavarkar SH, Madhu CK, Mule VD. A comparative study of teenage pregnancy. J Obstet Gynaecol. 2008;28(6):604-7.

15. Amed MAR, Mourad EM, Reda A, Abdel HM. Teenage pregnancy: are teenagers a high-risk group? Eu J Obstet Gynecol Reprod Biol. 1995;59(1):17-20.

16. Soula O, Carles G, Largeaud M, El Guindi W, Montoya Y. Pregnancy and childbirth among adolescents under 15 years of age: Study of 181 cases in French Guiana. J Obstet Gynecol Reprod. 2006;35(1):53-61.

Cite this article as: Théra T, Mounkoro N, Téguété I, Kouma A, Traoré ZO, Kanté I, Diarra E. Maternal and perinatal outcome of teenage deliveries in Bamako's district. Int J Reprod Contracept Obstet Gynecol 2017;6:4766-70. 